\title{
HÁBITOS DE LEITURA DE ESTUDANTES INGRESSANTES E CONCLUINTES DE UMA FACULDADE PRIVADA NO NORTE DO BRASIL
}

\section{READING HABITS OF STUDENTS INGRESSIVE AND CONCLUDING FROM A PRIVATE COLLEGE IN NORTH OF BRAZIL}

\section{HÁBITOS DE LECTURA DE ESTUDIANTES INGRESANTES Y QUE SE GRADÚAN DE UNA FACULTAD PRIVADA EN EL NORTE DE BRASIL}

\author{
Maria Romana Friedlander ${ }^{1}$, Ricardo Alexandre Duarte de Souza ${ }^{2}$, Simone Adriana Oelke ${ }^{3}$; Gerson Raiter ${ }^{4}$
}

Submetido: $16 / 07 / 2020$

Aprovado: 15/09/2020

\section{RESUMO}

Considerando-se a importância da universidade para a aquisição de hábitos de leitura como ferramenta para a inclusão do indivíduo na sociedade, o presente estudo tem como objetivo comparar os hábitos de leitura de estudantes de nível superior ingressantes e concluintes de uma faculdade privada situada na região do Norte do Brasil. Trata-se de uma pesquisa comparativa e descritiva com abordagem quantitativa realizada em uma faculdade privada situada na Região Norte do Brasil. A amostra populacional foi constituída por 153 estudantes ingressantes e 159 concluintes que representaram toda a população iniciante e finalista da instituição em estudo. As informações foram obtidas pela aplicação de um questionário e analisadas por parâmetros descritivos. Os principais resultados são: um aumento significativo dos estudantes concluintes que dizem "gostar de ler", um aumento da porcentagem desses alunos que preferem "revistas ou artigos científicos", uma acentuada diminuição no grupo dos concluintes que não leu nenhum livro no último ano e um importante decréscimo de finalistas que raramente leem. Os autores acreditam que os presentes resultados possam servir de parâmetro para novas investigações e que possam ter havido, além da maturidade e aumento da idade, alguma influência positiva do ensino acadêmico, mas pesquisas específicas devem ser realizadas.

PALAVRAS-CHAVE: Leitura; Universidades; Brasil

\section{ABSTRACT \\ Considering the importance of the University for the acquisition of reading habits as a tool for the inclusion of the individual in society, the present study aims to compare the reading habits of college-level students who are entering and graduating from a private college located in the northern region of Brazil. This is a comparative and descriptive research with a quantitative approach carried out in a private college located in the northern region of Brazil. The population sample consisted of 153 incoming students and 159 seniors who represented the entire beginner and finalist population of the institution under study. The information was obtained by applying a questionnaire and ana- lyzed by descriptive parameters. The main results are a significant increase in the number of senior students who say they "like to read", an increase in the percentage of those who prefer "journals or scientific articles", a sharp

\footnotetext{
${ }^{1}$ Instituto Educacional Santa Catarina, Faculdade Guaraí, Coordenadora de Pesquisa, Guaraí, Tocantins. E-mail: mariaromana1942@gmail.com

${ }^{2}$ Instituto Educacional Santa Catarina, Faculdade Guaraí, Docente do Curso de Administração e Coordenador de Tecnologia da Informação

${ }^{3}$ Instituto Educacional Santa Catarina, Faculdade Guaraí, Docente do Curso de Educação Física e Coordenadora Acadêmica.

${ }^{4}$ Instituto Educacional Santa Catarina, Faculdade Guaraí, Docente do Curso de Educação Física e Diretor da instituição.
} 
decrease in the group of graduates who did not read any books in the last year and an important decrease in finalists who rarely read. The authors believe that the present results may serve as a parameter for further investigations and that there may have been, in addition to maturity and increased age, some positive influence of academic education, but specific researches should be carried out.

KEYWORDS: Reading; Universities; Brasil

\section{RESUMEN}

Teniendo en cuenta la importancia de la universidad para adquirir hábitos de lectura como herramienta para la inclusión del individuo en la sociedad, el presente estudio tiene como objetivo comparar los hábitos de lectura de los estudiantes de nivel superior ingresantes y que se gradúan de una facultad privada ubicada en la región norte de Brasil. Se trata de una investigación comparativa y descriptiva, con abordaje cuantitativo, realizada en una facultad privada ubicada en la región norte de Brasil. La muestra poblacional ha sido constituida por 153 estudiantes ingresantes y 159 que se gradúan, que representaron toda la población iniciante y finalista de la institución en estudio. Las informaciones se obtuvieron a través del uso de una encuesta y se analizaron por parámetros descriptivos. Los principales resultados son: un aumento significativo de los estudiantes que se gradúan que afirman que "les gusta leer", un aumento del porcentaje de estos alumnos que prefieren "revistas o artículos científicos", una significativa disminución en el grupo de los que se gradúan que no leyó ningún libro en el último año y una importante reducción de finalistas que raramente leen. Los autores creen que los resultados presentes pueden servir como parámetro para nuevas investigaciones y que puede haber, además de la madurez y del aumento de la edad, una influencia positiva de la enseñanza académica, pero se deben realizar estudios específicos para ello.

PALABRAS CLAVE: Llectura; Universidades; Brasil 


\section{INTRODUÇÃO}

Podem-se definir hábitos de leitura como a forma individual de cada indivíduo organizar suas leituras. São adquiridos desde a infância e precisam ser estimulados e encorajados para que se tornem úteis e acompanhem o indivíduo por toda a sua vida ajudando-o a crescer, a moldar sua imaginação, desenvolver o controle de sua linguagem e de seus potenciais para que desempenhe um papel significativo na sociedade onde vive1. Esse mesmo autor mostra que vários pesquisadores demonstraram que o estímulo à leitura melhora os hábitos incluindo a frequência da leitura, o volume e os conteúdos escolhidos. Cita, também, uma pesquisa realizada em Bangladesh, em 2013, que conclui que os estudantes que não têm prazer em ler os textos relacionados ao curso queixam-se que os mesmos são muito difíceis, provocam ansiedade e não os motiva para estudar.

O processo de leitura é complexo e envolve aspectos, não só das características do texto e do contexto do momento em que ele é produzido2 como, também, aspectos do próprio leitor, seu contexto biológico, social, cultural e psicológico de vida e sua história em relação à leitura, incluindo influências do ambiente doméstico, social e escolar. A leitura e a compreensão de um texto exigem um leitor ativo, que compreenda as mensagens do texto guiado por suas vivências passadas. Paulo Freire, já em 1983, afirmava que a "leitura do mundo precede a leitura da palavra"3.

A universidade, como instituição responsável pela aprendizagem e formação do indivíduo em nível superior deve desempenhar um papel importante nesse encorajamento para a aquisição de hábitos benéficos ao desenvolvimento individual de cada ser humano e tornar o futuro profissional mais capacitado e competente no desempenho de suas funções sociais. Cabe à universidade o desafio de formar os futuros professores e pesquisadores o que compreende a aquisição das mais elevadas e complexas habilidades para lidar com o conhecimento, entre elas os métodos de pesquisa, estatística, aplicações de programas computacionais e habilidades acadêmicas ligadas à leitura e escrita1.

No Brasil, no período entre 1990 e 2006, a psicóloga Geraldine Porto Witter adotou como uma de suas linhas de pesquisa a relação entre Universidade, Psicologia e Leitura e sob esse tema publicou vasta literatura sob a forma de livros, artigos, dissertações e teses, entre eles, os livros "Psicologia, Leitura e Universidade"4, "Leitura: textos e pesquisas"5 e "Leitura e Psicologia"6 a partir da compilação e organização de textos e artigos científicos produzidos por seus grupos de pesquisa, no estado de São Paulo. Contudo, considerando-se que o Brasil é constituído por uma somatória de espaços sociais extremamente diferentes uns dos outros, percebe-se que a quantidade de estudos que produzem informações válidas sobre a leitura dos aprendizes dos vários níveis de escolaridade, ainda é pequena e as inúmeras falhas e carências existentes não permitem o retrato fiel da situação.

Tourinho em 20117, numa revisão bibliográfica, afirma que no Brasil não há pesquisas suficientes para ter-se a dimensão exata da problemática relacionada à leitura dos estudantes de um modo geral e particularmente, daqueles que frequentam as faculdades e universidades brasileiras. Afirma ainda que, a prática frequente da leitura é um instrumento importante para o exercício da cidadania e para a inclusão do indivíduo na sociedade.

Reforçando a opinião de Tourinho, em relação aos últimos 6 anos, uma busca da bibliografia encontrada, mostra resultados de várias regiões geográficas brasileiras, vários níveis de escolaridade e várias variáveis estudadas não permitindo um retrato consistente da situação de leitura dos universitários brasileiros e, muito menos, da influência da universidade nesses hábitos e habilidades. Foram selecionados 6 trabalhos publicados, brasileiros Silva et al8, Baptista et al.2, Araujo, Vazella e Brambila9, Garcia, Moraes e Guariente10, Lustosa et al.11 e Nascimento e Franco12.

Dos trabalhos mencionados, sobre os hábitos de leitura dos estudantes, um foi realizado em Pernambuco, outro na Paraíba, outro no Rio de Janeiro e três no estado do Paraná; 5 trabalhos referem-se a estudantes universitários de vários cursos superiores e um é referente a alunos dos $6^{\circ}$ e $7^{\circ}$ anos do ensino fundamental; 3 foram realizados em instituições públicas e $3 \mathrm{em}$ instituições de ensino privadas. Finalmente, em relação às variáveis estudadas, um dos estudos citados estudou a influência da universidade nos hábitos de leitura dos estudantes e 5 trabalhos afirmaram que a habilidade em ler e interpretar o texto são ferramentas importantes para a formação universitária. Ainda em relação às variáveis, um trabalho concluiu que os estudantes usam mais a internet que os livros ou material impresso; outro verificou que os estudantes que leem as matérias das aulas ao chegar em casa apresentaram escores mais altos na interpretação textual; o terceiro trabalho percebeu que a maioria dos estudantes lê com mais frequência 
romances, uma grande parte desses alunos só lê textos acadêmicos e alegam falta de tempo para a insuficiência de leitura. O quarto trabalho, com alunos ingressantes, mostrou que $81,7 \%$ afirmou que leem com frequência, $49,9 \%$ redige textos com facilidade e $57,3 \%$ diz que apresenta facilidade parcial para interpretar textos. Finalmente, uma pesquisa qualitativa concluiu que todos os respondentes afirmam que usam a internet como ferramenta de leitura para auxiliar as tarefas acadêmicas ou para obter notícias ou informações relacionadas às redes sociais, blogs, sobre esportes, celebridades ou política. As autoras afirmam que nenhum estudante demonstrou compreensão sobre a realidade na qual estão inseridos e suas relações com o contexto profissional ou social.

O que mais chamou a atenção foram os resultados de um dos trabalhos11 que demonstra que a maioria, tanto de ingressantes quanto de concluintes, apresenta um nível de alfabetização compatível com uma grande defasagem de prática de leitura oriunda do ensino básico, ou seja, as deficiências do básico mantêm-se no nível superior apesar da ação da universidade.

Considerando-se a importância da universidade para a aquisição de hábitos de leitura como ferramenta para a inclusão do indivíduo na sociedade, a carência de informações consistentes sobre essas variáveis, a necessidade de aprimorar as iniciativas do ensino superior e as particularidades da região norte brasileira, o presente estudo tem como objetivo comparar os hábitos de leitura de estudantes de nível superior ingressantes e concluintes de uma faculdade privada situada na região do Norte do Brasil. Os resultados deste estudo poderão auxiliar na formação de um retrato mais completo deste tema em relação à população estudantil dessa região brasileira e, consequentemente, auxiliar nos diagnósticos da problemática, bem como na adequação de iniciativas que visem minimizar ou solucionar a problemática exposta.

\section{MATERIAIS E MÉTODOS}

Trata-se de uma pesquisa descritiva e comparativa com abordagem quantitativa realizada em uma faculdade privada localizada na região central do estado do Tocantins que conta com 1600 estudantes matriculados em 11 cursos de graduação.

A população foi constituída por 312 estudantes, sendo 153 matriculados no segundo período e 159 no último período dos seguintes cursos: Biomedicina, En- fermagem, Direito, Agronomia, Administração de Empresas, Fisioterapia, Pedagogia e Educação Física. Os critérios de inclusão foram: serem maiores de idade, estarem matriculados no segundo ou no último semestre de um dos 8 cursos citados acima, estarem presentes no dia da aplicação do questionário e concordarem com o seu preenchimento.

O instrumento de coleta foi composto por um questionário elaborado a partir de bibliografia sobre o tema1, 2,8,9,11,13,14 e constou de quatro partes: Termo de Compromisso Livre e Esclarecido (TCLE), características populacionais, características contextuais e hábitos de leitura. Esse instrumento foi testado por meio de aplicação em estudantes da mesma faculdade que não fariam parte da população do estudo, mas tinham características similares à população pesquisada.

Dois dos autores, entregaram os questionários aos estudantes das classes selecionadas e antes do preenchimento em sala de aula, o TCLE foi lido em voz alta e destacados os direitos dos respondentes e as garantias oferecidas pelos pesquisadores; os menores de idade foram rejeitados com os devidos esclarecimentos.

O projeto da pesquisa foi submetido à apreciação do Comitê de Pesquisa do Centro Universitário Luterano de Palmas e recebeu o número do CAAE 88459918.5.0000.5516. Foi aprovado em 07 de junho de 2018.

Os dados obtidos foram passados para uma planilha Excel apropriada e a análise utilizou apenas a estatística descritiva com números absolutos e porcentuais. Para fins da discussão foram consideradas diferenças relevantes apenas as maiores de $10 \%$.

\section{RESULTADOS}

Quanto às características populacionais, pode-se verificar na Tabela 1 que a população é composta por 153 estudantes ingressantes e 159 concluintes, dos 8 cursos citados, em proporções diferentes, sem, no entanto, haver uma hegemonia acentuada de nenhum dos cursos estudados. Outra característica populacional a destacar é que a diferença entre o número de ingressantes e concluintes é desprezível. 
Tabela 1 - Número e porcentagem de alunos ingressantes e concluintes pelos cursos participantes da população do estudo. Guaraí. 2018.

\begin{tabular}{|c|c|c|c|c|c|c|}
\hline \multirow{2}{*}{$\begin{array}{l}\text { CURSO } \\
\text { FREQUENTADO }\end{array}$} & \multicolumn{2}{|c|}{$\begin{array}{c}\text { Alunos } \\
\text { Ingressantes }\end{array}$} & \multicolumn{2}{|c|}{$\begin{array}{c}\text { Alunos } \\
\text { Concluintes } \\
\end{array}$} & \multicolumn{2}{|c|}{ TOTAIS } \\
\hline & $\mathrm{N}^{\circ}$ & $\%$ & $\mathrm{~N}^{\circ}$ & $\%$ & $\mathrm{~N}^{\circ}$ & $\%$ \\
\hline Administração & 8 & $5,2 \%$ & 14 & $8,8 \%$ & 22 & $7,1 \%$ \\
\hline Agronomia & 19 & $12,4 \%$ & 18 & $11,3 \%$ & 37 & $11,9 \%$ \\
\hline Biomedicina & 14 & $9,2 \%$ & 17 & $10,7 \%$ & 31 & $9,9 \%$ \\
\hline Direito & 30 & $19,6 \%$ & 20 & $12,6 \%$ & 50 & $16,0 \%$ \\
\hline Educação Física & 9 & $5,9 \%$ & 20 & $12,6 \%$ & 29 & $9,3 \%$ \\
\hline Enfermagem & 22 & $14,4 \%$ & 20 & $12,6 \%$ & 42 & $13,5 \%$ \\
\hline Fisioterapia & 29 & $19,0 \%$ & 27 & $17,0 \%$ & 56 & $17,9 \%$ \\
\hline Pedagogia & 22 & $14,4 \%$ & 23 & $14,5 \%$ & 45 & $14,4 \%$ \\
\hline Total & 153 & $100 \%$ & 159 & $100 \%$ & 312 & $100 \%$ \\
\hline
\end{tabular}

Os principais destaques no Quadro 1 são: a) verifica-se um grande aumento dos estudantes concluintes que vivem com companheiro; b) a faixa etária da maioria dos concluintes sofreu um importante aumento se comparada com a dos ingressantes; c) percebe-se a preponderância do sexo feminino em ambos os grupos, ingressantes e concluintes; d) a renda da maioria da população concentra-se na faixa de 1 até 3 salários-mínimos, em ambos os grupos; e) destaca-se a origem urbana da população, tanto do município de Guaraí como dos municípios vizinhos, em ambos os grupos.

Quadro 1 - Características sócio demográficas da população. Guaraí. 2018.

\begin{tabular}{|c|c|c|c|c|c|c|}
\hline \multirow{2}{*}{$\begin{array}{l}\text { ESTADO } \\
\text { CONJUGAL* }\end{array}$} & \multicolumn{2}{|c|}{$\begin{array}{c}\text { Alunos } \\
\text { Ingressantes }\end{array}$} & \multicolumn{2}{|c|}{$\begin{array}{c}\text { Alunos } \\
\text { Concluintes }\end{array}$} & \multicolumn{2}{|c|}{ TOTAIS } \\
\hline & $\mathrm{N}^{0}$ & $\%$ & $\mathrm{~N}^{0}$ & $\%$ & $\mathrm{~N}^{0}$ & $\%$ \\
\hline $\begin{array}{l}\text { Sem } \\
\text { companheiro }\end{array}$ & 125 & $58,4 \%$ & 89 & $41,6 \%$ & 214 & $100 \%$ \\
\hline $\begin{array}{l}\text { Com } \\
\text { companheiro }\end{array}$ & 27 & $30,0 \%$ & 63 & $70,0 \%$ & 90 & $100 \%$ \\
\hline Total & 152 & & 152 & & 304 & \\
\hline \multirow{2}{*}{$\begin{array}{l}\text { RENDA } \\
\text { MENSAL } \\
\text { (Familiar, em } \\
\text { salários } \\
\text { mínimos) }\end{array}$} & \multicolumn{2}{|c|}{$\begin{array}{l}\text { Alunos In- } \\
\text { gressantes }\end{array}$} & \multicolumn{2}{|c|}{$\begin{array}{c}\text { Alunos } \\
\text { Concluintes }\end{array}$} & \multicolumn{2}{|c|}{ TOTAIS } \\
\hline & $\mathrm{N}^{0}$ & $\%$ & $\mathrm{~N}^{\circ}$ & $\%$ & $\mathrm{~N}^{\circ}$ & $\%$ \\
\hline $\mathrm{De} 1$ a $3 \mathrm{~s} . \mathrm{m}$. & 129 & $50,4 \%$ & 127 & $49,6 \%$ & 256 & $100 \%$ \\
\hline De 4 a 6 s. m. & 18 & $38,3 \%$ & 29 & $61,7 \%$ & 47 & $100 \%$ \\
\hline De 7 a 10 s. m. & 3 & $60,0 \%$ & 2 & $40,0 \%$ & 5 & $100 \%$ \\
\hline $\begin{array}{l}\text { Mais de } 10 \mathrm{~s} \text {. } \\
\mathrm{m} \text {. }\end{array}$ & 3 & $75,0 \%$ & 1 & $25,0 \%$ & 4 & $100 \%$ \\
\hline Total & 153 & & 159 & & 312 & \\
\hline \multirow[t]{2}{*}{ SEXO* } & \multicolumn{2}{|c|}{$\begin{array}{c}\text { Alunos } \\
\text { Ingressantes }\end{array}$} & \multicolumn{2}{|c|}{$\begin{array}{c}\text { Alunos } \\
\text { Concluintes } \\
\end{array}$} & \multicolumn{2}{|c|}{ TOTAIS } \\
\hline & $\mathrm{N}^{\circ}$ & $\%$ & $\mathrm{~N}^{\circ}$ & $\%$ & $\mathrm{~N}^{\circ}$ & $\%$ \\
\hline Masculino & 50 & $48,5 \%$ & 53 & $51,5 \%$ & 103 & $100 \%$ \\
\hline Feminino & 103 & $49,8 \%$ & 104 & $50,2 \%$ & 207 & $100 \%$ \\
\hline Total & 153 & & 157 & & 310 & \\
\hline
\end{tabular}

\begin{tabular}{|c|c|c|c|c|c|c|}
\hline \multirow{2}{*}{$\begin{array}{l}\text { FAIXA ETÁRIA } \\
{\text { (anos) })^{*}}^{*}\end{array}$} & \multicolumn{2}{|c|}{$\begin{array}{c}\text { Alunos } \\
\text { Ingressantes }\end{array}$} & \multicolumn{2}{|c|}{$\begin{array}{c}\text { Alunos } \\
\text { Concluintes }\end{array}$} & \multicolumn{2}{|c|}{ TOTAIS } \\
\hline & $\mathrm{N}^{\circ}$ & $\%$ & $\mathrm{~N}^{\circ}$ & $\%$ & $\mathrm{~N}^{\circ}$ & $\%$ \\
\hline$<20$ & 88 & $94,6 \%$ & 5 & $5,4 \%$ & 93 & $100 \%$ \\
\hline $20-30$ & 54 & $32,9 \%$ & 110 & $67,1 \%$ & 164 & $100 \%$ \\
\hline$>30$ & 9 & $17,6 \%$ & 42 & $82,4 \%$ & 51 & $100 \%$ \\
\hline Total & 151 & & 157 & & 308 & \\
\hline \multirow{2}{*}{$\begin{array}{l}\text { LOCAL DE } \\
\text { RESIDÊNCIA* }\end{array}$} & \multicolumn{2}{|c|}{$\begin{array}{c}\text { Alunos } \\
\text { Ingressantes }\end{array}$} & \multicolumn{2}{|c|}{$\begin{array}{c}\text { Alunos } \\
\text { Concluintes }\end{array}$} & \multicolumn{2}{|c|}{ TOTAIS } \\
\hline & $\mathrm{N}^{\circ}$ & $\%$ & $\mathrm{~N}^{\circ}$ & $\%$ & $\mathrm{~N}^{0}$ & $\%$ \\
\hline $\begin{array}{l}\text { Zona Urbana } \\
\text { Guaraí }\end{array}$ & 88 & $49,4 \%$ & 90 & $50,6 \%$ & 178 & $100 \%$ \\
\hline $\begin{array}{l}\text { Zona Rural } \\
\text { Guaraí }\end{array}$ & 2 & $50,0 \%$ & 2 & $50,0 \%$ & 4 & $100 \%$ \\
\hline $\begin{array}{l}\text { Zona urbana } \\
\text { cidade vizinha }\end{array}$ & 58 & $46,8 \%$ & 66 & $53,2 \%$ & 124 & $100 \%$ \\
\hline $\begin{array}{l}\text { Zona Rural } \\
\text { cidade vizinha }\end{array}$ & 4 & $80,0 \%$ & 1 & $20,0 \%$ & 5 & $100 \%$ \\
\hline Total & 152 & & 159 & & 311 & \\
\hline
\end{tabular}

* Alguns alunos não responderam esta questão

Há poucos destaques na Quadro 2, a qual abrange as características do contexto dos elementos populacionais. Estabelecendo-se a comparação entre alunos ingressantes e concluintes, nota-se, nesse quadro: a) um aumento de alunos concluintes que trabalham e estudam; b) a maioria dos alunos de ambos os grupos são provenientes de escolas públicas; c) a maior parte dos estudantes são oriundos de famílias com boa escolaridade, $62,9 \%$ das mães e $39,2 \%$ dos pais tem 9 ou mais anos de estudo; d) 20,9\% das famílias não têm o hábito de ler mas, $59,2 \%$ das famílias lê raramente ou com frequência; e) somente $19,9 \%$ das famílias estimulam os jovens a lerem. Estes resultados serão discutidos posteriormente.

Quadro 2- Características contextuais dos estudantes ingressantes e concluintes. Guaraí. 2018.

\begin{tabular}{|c|c|c|c|c|c|c|}
\hline \multirow[t]{2}{*}{ TRABALHO } & \multicolumn{2}{|c|}{$\begin{array}{c}\text { Alunos } \\
\text { Ingressantes }\end{array}$} & \multicolumn{2}{|c|}{$\begin{array}{c}\text { Alunos } \\
\text { Concluintes }\end{array}$} & \multicolumn{2}{|c|}{ TOTAIS } \\
\hline & $\mathrm{N}^{0}$ & $\%$ & $\mathrm{~N}^{0}$ & $\%$ & $\mathrm{~N}^{0}$ & $\%$ \\
\hline $\begin{array}{l}\text { Exerce } \\
\text { atividade } \\
\text { remunerada e } \\
\text { estuda }\end{array}$ & 85 & $43,6 \%$ & 110 & $56,4 \%$ & 195 & $100 \%$ \\
\hline Só estuda & 68 & $58,1 \%$ & 49 & $41,9 \%$ & 117 & $100 \%$ \\
\hline Total & 153 & & 159 & & 312 & \\
\hline \multirow{2}{*}{$\begin{array}{l}\text { Ensino médio } \\
\text { frequentado* }\end{array}$} & \multicolumn{2}{|c|}{$\begin{array}{c}\text { Alunos } \\
\text { Ingressantes }\end{array}$} & \multicolumn{2}{|c|}{$\begin{array}{c}\text { Alunos } \\
\text { Concluintes }\end{array}$} & \multicolumn{2}{|c|}{ TOTAIS } \\
\hline & $\mathrm{N}^{0}$ & $\%$ & $\mathrm{~N}^{0}$ & $\%$ & $\mathrm{~N}^{0}$ & $\%$ \\
\hline Público & 135 & $47,4 \%$ & 150 & $52,6 \%$ & 285 & $100 \%$ \\
\hline Privado & 7 & $58,3 \%$ & 5 & $41,7 \%$ & 12 & $100 \%$ \\
\hline $\begin{array}{l}\text { Público e } \\
\text { Privado }\end{array}$ & 9 & $81,8 \%$ & 2 & $18,2 \%$ & 11 & $100 \%$ \\
\hline Total & 151 & & 157 & & 308 & \\
\hline
\end{tabular}




\begin{tabular}{|c|c|c|c|c|c|c|}
\hline \multirow{2}{*}{\begin{tabular}{|l} 
NIIVEL DE \\
ESCOLAR- \\
IDADE DA \\
MÃE \\
$\left(n^{0} \text { de anos) }\right)^{*}$ \\
\end{tabular}} & \multicolumn{2}{|c|}{$\begin{array}{c}\text { Alunos } \\
\text { Ingressantes }\end{array}$} & \multicolumn{2}{|c|}{$\begin{array}{c}\text { Alunos } \\
\text { Concluintes }\end{array}$} & \multicolumn{2}{|c|}{ TOTAIS } \\
\hline & $N^{\circ}$ & $\%$ & $\mathrm{~N}^{\circ}$ & $\%$ & $\mathrm{~N}^{\circ}$ & $\%$ \\
\hline Analfabeto & 2 & $16,7 \%$ & 10 & $83,3 \%$ & 12 & $100 \%$ \\
\hline $1-4$ & 11 & $68,8 \%$ & 5 & $31,3 \%$ & 16 & $100 \%$ \\
\hline $4-8$ & 29 & $46,8 \%$ & 33 & $53,2 \%$ & 62 & $100 \%$ \\
\hline 9 ou mais & 91 & $46,7 \%$ & 104 & $53,3 \%$ & 195 & $100 \%$ \\
\hline Desconhece & 18 & $72,0 \%$ & 7 & $28,0 \%$ & 25 & $100 \%$ \\
\hline Total & 151 & & 159 & & 310 & \\
\hline \multirow{2}{*}{$\begin{array}{l}\text { NIVEL DE } \\
\text { ESCOLARI- } \\
\text { DADE DO PAI } \\
\left(n^{\circ} \text { de anos) }\right)^{\star}\end{array}$} & \multicolumn{2}{|c|}{$\begin{array}{c}\text { Alunos } \\
\text { Ingressantes }\end{array}$} & \multicolumn{2}{|c|}{$\begin{array}{c}\text { Alunos } \\
\text { Concluintes }\end{array}$} & \multicolumn{2}{|c|}{ TOTAIS } \\
\hline & $\mathrm{N}^{0}$ & $\%$ & $\mathrm{~N}^{0}$ & $\%$ & $\mathrm{~N}^{0}$ & $\%$ \\
\hline Analfabeto & 4 & $26,7 \%$ & 11 & $73,3 \%$ & 15 & $100 \%$ \\
\hline $1-4$ & 14 & $60,9 \%$ & 9 & $39,1 \%$ & 23 & $100 \%$ \\
\hline $4-8$ & 31 & $34,1 \%$ & 60 & $65,9 \%$ & 91 & $100 \%$ \\
\hline 9 ou mais & 63 & $52,5 \%$ & 57 & $47,5 \%$ & 120 & $100 \%$ \\
\hline Desconhece & 35 & $61,4 \%$ & 22 & $38,6 \%$ & 57 & $100 \%$ \\
\hline \begin{tabular}{|l|} 
Total \\
\end{tabular} & 147 & & 159 & & 306 & \\
\hline \multirow{2}{*}{$\begin{array}{l}\text { HÁBITOS DA } \\
\text { FAMÍLIA* }^{*}\end{array}$} & \multicolumn{2}{|c|}{$\begin{array}{c}\text { Alunos } \\
\text { Ingressantes }\end{array}$} & \multicolumn{2}{|c|}{$\begin{array}{c}\text { Alunos } \\
\text { Concluintes }\end{array}$} & \multicolumn{2}{|c|}{ TOTAIS } \\
\hline & $\mathrm{N}^{\circ}$ & $\%$ & $\mathrm{~N}^{0}$ & $\%$ & $\mathrm{~N}^{0}$ & $\%$ \\
\hline $\begin{array}{l}\text { Lê com } \\
\text { frequência }\end{array}$ & 27 & $38,6 \%$ & 43 & $61,4 \%$ & 70 & $100 \%$ \\
\hline Lê raramente & 57 & $51,4 \%$ & 54 & $48,6 \%$ & 111 & $100 \%$ \\
\hline Não lê & 33 & $51,6 \%$ & 31 & $48,4 \%$ & 64 & $100 \%$ \\
\hline \begin{tabular}{|l|} 
Estimula sua \\
leitura
\end{tabular} & 32 & $52,5 \%$ & 29 & $47,5 \%$ & 61 & $100 \%$ \\
\hline Total & 149 & & 157 & & 306 & \\
\hline
\end{tabular}

* Alguns estudantes não informaram esta variável

Em relação aos hábitos de leitura, mostrados na Quadro 3, características estas que se relacionam diretamente com o objetivo da pesquisa, destaca-se: a) No item "gostar de ler" percebeu-se um aumento na porcentagem dos alunos concluintes e, coerentemente, uma diminuição dos estudantes ingressantes que informaram "não gostar de ler"; b) o livro, seja religioso ou acadêmico, foi o item mais citado dos gêneros de leitura preferidos, $80,1 \%$ de alunos o citaram como preferido; c) No gênero de leitura preferido também aumentou a porcentagem dos alunos concluintes que preferiam as "revistas ou artigos científicos" e, uma diminuição dos mesmos alunos que preferiam "histórias em quadrinhos". Houve um leve aumento na preferência da leitura de jornais entre os concluintes; d) na comparação entre os dois grupos de estudantes, encontrou-se uma diminuição muito importante no número de alunos concluintes que não leu nenhum livro durante o último ano, de $65,2 \%$ para 34,8\%; e) Em relação aos locais de leitura, o trabalho, coerentemente, mostrou um leve aumento porcentual entre os concluintes; f) os resultados também mostram um aumento na porcentagem dos concluintes que afirmam ler semanalmente e, uma diminuição daqueles estudantes concluintes que raramente leem; g) finalmente, um aumento dos concluintes que prefere o formato impresso.

Quadro 3 - Características relacionadas aos hábitos de leitura dos estudantes ingressantes e concluintes.

\begin{tabular}{|c|c|c|c|c|c|c|}
\hline \multirow{2}{*}{$\begin{array}{l}\text { GOSTAR } \\
\text { DE LER* }\end{array}$} & \multicolumn{2}{|c|}{$\begin{array}{c}\text { Alunos } \\
\text { Ingressantes }\end{array}$} & \multicolumn{2}{|c|}{$\begin{array}{c}\text { Alunos } \\
\text { Concluintes }\end{array}$} & \multicolumn{2}{|c|}{ TOTAIS } \\
\hline & $\mathrm{N}^{\circ}$ & $\%$ & $\mathrm{~N}^{0}$ & $\%$ & $\mathrm{~N}^{0}$ & $\%$ \\
\hline Sim & 63 & $3,2 \%$ & 3 & $6,8 \%$ & 146 & $00^{\circ}$ \\
\hline & 4 & $28,6 \%$ & 10 & $71,4 \%$ & 14 & $100^{\circ}$ \\
\hline 10 & 5 & $\%$ & 66 & $3,7 \%$ & 151 & 100 \\
\hline tal & 152 & & 159 & & 311 & \\
\hline \multirow{2}{*}{$\begin{array}{l}\text { Gênero de } \\
\text { leitura } \\
\text { preferido }\end{array}$} & \multicolumn{2}{|c|}{$\begin{array}{c}\text { Alunos } \\
\text { Ingressantes }\end{array}$} & \multicolumn{2}{|c|}{$\begin{array}{c}\text { Alunos } \\
\text { Concluintes }\end{array}$} & \multicolumn{2}{|c|}{ TOTAIS } \\
\hline & $\mathrm{N}^{\circ}$ & $\%$ & $\mathrm{~N}^{\circ}$ & $\%$ & $\mathrm{~N}^{0}$ & $\%$ \\
\hline Livros ou & 55 & $\%$ & 57 & $50,9 \%$ & 112 & 100 \\
\hline & 69 & $50,0 \%$ & 69 & $50,0 \%$ & 138 & 10 \\
\hline & 26 & $33,8 \%$ & 51 & $66,2 \%$ & 77 & 100 \\
\hline 0 & 20 & $48,8 \%$ & 21 & $51,2 \%$ & 41 & 100 \\
\hline & & $\%$ & 6 & $9,0 \%$ & 1 & 00 \\
\hline $\begin{array}{l}\text { Sites } \\
\text { cias }\end{array}$ & 94 & $49,5 \%$ & 96 & $50,5 \%$ & 190 & 100 \\
\hline & 2 & $61,5 \%$ & 20 & $\%$ & 52 & $100 \%$ \\
\hline Out & & $0 \%$ & & $0,0 \%$ & 0 & 100 \\
\hline Toté & 326 & & 355 & & 681 & \\
\hline $\begin{array}{l}\text { Quantida } \\
\text { livros }\end{array}$ & \multicolumn{2}{|c|}{$\begin{array}{c}\text { Alunos } \\
\text { Ingressantes }\end{array}$} & \multicolumn{2}{|c|}{$\begin{array}{c}\text { Alunos } \\
\text { Concluintes } \\
\end{array}$} & \multicolumn{2}{|c|}{ TOTAIS } \\
\hline & $\mathrm{N}^{\circ}$ & $\%$ & $1^{\circ}$ & $\%$ & $\mathrm{~N}^{\circ}$ & $\%$ \\
\hline Nenhum & & 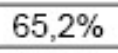 & 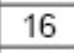 & $8 \%$ & 6 & $100^{\circ}$ \\
\hline & & $4 \%$ & 0 & $2,6 \%$ & 76 & $100 \%$ \\
\hline & & $\%$ & 6 & $55,9 \%$ & 136 & $100 \%$ \\
\hline Mais de 4 & 26 & 4 & 27 & $50,9 \%$ & 3 & 1( \\
\hline lot & 152 & & 159 & & 11 & \\
\hline \multirow{2}{*}{$\begin{array}{l}\text { Locais onde } \\
\text { costuma ler }\end{array}$} & \multicolumn{2}{|c|}{$\begin{array}{c}\text { Alunos } \\
\text { Ingressantes }\end{array}$} & \multicolumn{2}{|c|}{$\begin{array}{c}\text { Alunos } \\
\text { Concluintes }\end{array}$} & \multicolumn{2}{|c|}{ TOTAIS } \\
\hline & $\mathrm{N}^{\circ}$ & o & $\mathrm{N}^{\circ}$ & $\%$ & $\mathrm{~N}^{\circ}$ & $\%$ \\
\hline & 58 & $50,4 \%$ & 57 & $\%$ & 15 & $100 \%$ \\
\hline Trabal & 1 &, $7 \%$ & 1 & $60,3 \%$ & 78 & $100 \%$ \\
\hline Cas & 137 & $00,0 \%$ & 137 & $50,0 \%$ & 274 & 100 \\
\hline Igreja & 13 & $43,3 \%$ & 17 & $56,7 \%$ & 30 & $100^{\circ}$ \\
\hline
\end{tabular}




\begin{tabular}{|c|c|c|c|c|c|c|}
\hline tros & 1 & 0,0 & 4 & $\circ$ & 5 & 100 \\
\hline Total & 240 & & 262 & & 502 & \\
\hline \multirow{2}{*}{$\begin{array}{l}\text { Frequência da } \\
\text { leitura }\end{array}$} & \multicolumn{2}{|c|}{$\begin{array}{c}\text { Alunos } \\
\text { Ingressantes }\end{array}$} & \multicolumn{2}{|c|}{$\begin{array}{c}\text { Alunos } \\
\text { Concluintes }\end{array}$} & \multicolumn{2}{|c|}{ TOTAIS } \\
\hline & $\mathrm{N}^{\circ}$ & $\%$ & $\mathrm{~N}^{\circ}$ & $\%$ & $\mathrm{~N}^{0}$ & $\%$ \\
\hline ari & 40 & $6,7 \%$ & 8 & $3,3 \%$ & 0 & \\
\hline sem & 43 & $43,9 \%$ & 55 & $56,1 \%$ & 98 & 100 \\
\hline $\bar{M}$ & & $0 \%$ & 5 & $0 \%$ & 50 & 00 \\
\hline Rara & 0 & $57,1 \%$ & 30 & $42,9 \%$ & 70 & 100 \\
\hline Total & 150 & & 158 & & 308 & \\
\hline \multirow{2}{*}{$\begin{array}{l}\text { Formato } \\
\text { mais utilizado } \\
\text { durante as } \\
\text { leituras* }\end{array}$} & \multicolumn{2}{|c|}{$\begin{array}{c}\text { Alunos } \\
\text { Ingressantes }\end{array}$} & \multicolumn{2}{|c|}{$\begin{array}{c}\text { Alunos } \\
\text { Concluintes } \\
\end{array}$} & \multicolumn{2}{|c|}{ TOTAIS } \\
\hline & $\mathrm{N}^{\circ}$ & $\%$ & $\mathrm{~N}^{\circ}$ & $\%$ & $\mathrm{~N}^{0}$ & $\%$ \\
\hline Em formato & 41 & 5 & 38 & $48,1 \%$ & 79 & 10 \\
\hline 0 & 22 & 4 & 32 & 59 & 54 & 1 \\
\hline Em ambos os & 88 & $49,7 \%$ & 89 & $50,3 \%$ & 177 & 100 \\
\hline Total & 151 & & 159 & & 310 & \\
\hline
\end{tabular}

${ }^{*}$ Alguns estudantes não informaram esta variável

${ }^{* *}$ Alguns estudantes indicaram mais que uma opção

\section{DISCUSSÃO}

O fato da população do estudo não contar com a hegemonia de um dos cursos, como demonstrado na Tabela 1, é muito favorável porque argumenta a favor da população representar, de fato, toda a faculdade. Outro fato que colabora com a comparação pretendida neste estudo, é a semelhança entre o número absoluto de ingressantes e concluintes.

O perfil dos participantes é muito semelhante ao de outras pesquisas com estudantes universitários $8,9,10,11,15,16$ no que tange às variáveis: estado civil, faixa etária e sexo, o que indica uma coleta de dados confiável. O aumento dos alunos concluintes que vive com companheiro, bem como a respectiva faixa etária era esperado pelo aumento da idade e da maturidade deste grupo. Finalmente, em relação à renda familiar dos estudantes de ambos os grupos cuja maioria se situa entre 1 e 3 salários-mínimos, é similar aos encontrados por Silva et al.8; Lustosa et al.11, mas difere significativamente dos resultados descritos por Garcia, Moraes e Guariente10 e Alves et al.16 que encontraram a maioria da população auferindo uma renda familiar entre 5 e 10 salários-mínimos. Note-se que essas últimas pesquisas foram realizadas em universidades governamentais onde é frequente, como se sabe, os estudantes originarem-se de colégios particulares com um ensino de alta qualidade.

O número de estudantes concluintes que trabaIha aumentou quando comparado ao grupo de ingressantes, resultado este compatível com o aumento da maturidade, aumento do número de estudantes vivendo com companheiro e nível baixo da renda familiar. Outros estudos no Brasil realizados em faculdades privadas apontam similaridade de resultados, tais como, Lustosa et al11.

No presente estudo, ficou claro que a maioria de ambos os grupos é proveniente de escola pública. A bibliografia10,15 reforça a ideia de que nas universidades particulares, como é o caso do presente estudo, encontram-se mais alunos oriundos de escola de ensino médio pública e oferecem mais cursos noturnos o que não ocorre nas instituições de ensino superior governamentais 10,15,16. Assim, os alunos, com média de renda familiar mais baixa podem trabalhar e estudar simultaneamente.

A escolaridade dos pais dos estudantes da amostra populacional é alta uma vez que a maior parte tem nível superior. Este resultado é similar ao apresentado por outros pesquisadores, tais como: Lustosa et al.11, Gomes e Mandra15 e Alves et al.16.

Em relação aos hábitos de ler familiares não foram encontradas muitas informações bibliográficas que auxiliassem a interpretar os achados deste estudo. Entretanto, Garcia, Moraes e Guariente10, em faculdade privada, citam que $52,4 \%$ de estudantes afirmaram que suas famílias os estimulam a ler, porcentagem muito maior que o resultado encontrado neste estudo. Seria previsível a existência de influência nos jovens de pais e mães habituados a lerem. Entretanto, o estímulo à leitura provido pela família só foi percebido por cerca de $20 \%$ dos alunos participantes desta pesquisa. Talvez a necessidade do pai e mãe trabalharem em tempo integral devido à baixa renda familiar, explique esse baixo porcentual.

O primeiro destaque no Quadro 3 refere-se ao item "gostar de ler". Percebeu-se que houve um aumento desta variável entre os alunos concluintes, passou de $43,2 \%$ para $56,8 \%$, mas no conjunto dos dois grupos a percentagem é baixa (não chega a 47\%). A bibliografia cita que o estudante de nível superior afirma gostar de ler; os autores encontraram porcentagens entre $80 \% \mathrm{e}$ $90 \%$ nesta variável 10,11,16. Acredita-se que vários fatores colaborem para esta baixa porcentagem entre os alunos pesquisados: baixa renda familiar que obriga o jovem a estudar e trabalhar, localização da faculdade em 
município pequeno com pouco estímulo cultural e pouco estímulo familiar. Quanto ao gênero de leitura preferido, o livro, como item preferido por uma alta porcentagem de estudantes $(80,1 \%)$ concorda com os achados de outros autores 11,16. Garcia, Moraes e Guariente10 em faculdade governamental encontraram a revista como o gênero preferido por $72,3 \%$ de estudantes de enfermagem, seguido por livro por $60,4 \%$ de estudantes.

$O$ resultado de maior interesse para a faculdade foi a diferença entre o porcentual de alunos concluintes que afirma ler "revistas ou artigos científicos" comparado com a mesma porcentagem dos alunos ingressantes. Essa porcentagem duplicou. A maturidade do estudante concluinte frente à responsabilidade com sua profissão terá influenciado esse aumento, mas acredita-se que as estratégias da faculdade possam ter tido também alguma influência. Não foi encontrada bibliografia que possibilite comparações. De qualquer forma este achado pode constituir-se em parâmetro para a faculdade em questão avaliar futuras estratégias implementadas com a finalidade de melhorar os hábitos de leitura estudantis. Também o aumento, entre os concluintes, de interessados em leitura de jornais é coerente com Nascimento e Franco12 que afirma serem os jornais o gênero preferido dos estudantes que utilizam a internet como ferramenta para atualização. O aumento do trabalho como local de leitura dos alunos concluintes é coerente com as demais informações encontradas.

Outro resultado de grande interesse para a faculdade está relacionado com a quantidade de livros lidos no último ano. Encontrou-se apenas $34,8 \%$ de alunos concluintes que respondeu não haver lido "nenhum" livro no ano contra os $65,2 \%$ dos ingressantes que respondeu o mesmo. Coerentemente, a resposta "de 2 a 4 livros" lidos no ano recebeu 55,9\% de respostas dos concluintes, contra $44,1 \%$ dos ingressantes. A explicação para este dado pode ser uma somatória da maturidade estudantil com o ensino da faculdade. Silva et al.8 relatam que encontraram $21 \%$ de estudantes que dizem não ter lido nenhum livro nos últimos 12 meses e $25 \%$ que afirmam ter lido de 1 a 2 livros. Araujo, Vanzella e Brambilla 9, encontraram $7 \%$ de respostas para "nenhum", 26,23\% para "um livro" e 38,14\% para "de 2 a 3 livros". Gomes e Mandrá 15, encontraram 20,17\% de estudantes que responderam "nenhum livro" e 41,2\% para a resposta "no máximo dois". As três pesquisas citadas foram realizadas em instituições de ensino superior públicas.

O presente estudo demonstra que o local de tra- balho foi citado como o preferido por 39,7 dos alunos ingressantes e 60,3\% dos alunos concluintes. Este resultado é coerente com o aumento dos alunos concluintes que trabalha, contudo, não é similar ao encontrado por outros autores. Lustosa et al.11 e Araujo, Vanzella e Brambilla9 encontraram porcentagens mais significativas para a residência do estudante como local preferido para lerem. Não existem dados para fundamentar alguma hipótese de explicação.

Outro resultado também de importância para a faculdade é o aumento da porcentagem de concluintes, comparados com os ingressantes, que afirmam ler diariamente e semanalmente, de $85(27,2 \%)$ ingressantes para $118(37,8 \%)$ concluintes. Talvez esse resultado tenha sofrido influência da faculdade, como foi afirmado na discussão das variáveis anteriores. Essa porcentagem de alunos concluintes é similar à de Silva et al.8 que também afirma que $36 \%$ de alunos, universitários da rede privada, lê diariamente. No entanto, Gomes e Mandrá15 encontraram 40,9\% estudantes de faculdade pública que leem semanalmente. A pesquisa de Araujo, Vanzella e Brambilla9, em universidade pública, encontrou $66,7 \%$ de estudantes que afirmam ler diária ou semanalmente.

Finalmente, o fato de maior porcentagem $(59,3 \%)$ de nossos alunos concluintes preferirem o livro impresso ao digital e, só $40,7 \%$ dos alunos ingressantes terem a mesma preferência só encontrou similaridade na pesquisa de Alves et al.16. Outros autores11,15obtiveram melhores resultados para a utilização de formatos digitais.

Quando se comparam dois grupos de jovens em diferentes etapas da vida estudantil, no caso, ingressantes e concluintes, podem-se prever alterações ocasionadas pelo aumento da idade e respectiva maturidade física, psíquica e socioeconômica e sua presença reforça a confiabilidade dos dados coletados. No caso do presente estudo, esse tipo de alteração influenciou diretamente no aumento entre os concluintes, da faixa etária, da vida conjugal com companheiro, do número de discentes que trabalham e estudam simultaneamente, do gosto pela leitura, do gênero de leitura preferido, da frequência da leitura e da quantidade de livros lidos no último ano.

Entretanto, verifica-se que a influência da faculdade não pode ser desprezada porque existem estudos que comprovam o estímulo dos professores na melhoria desses hábitos. Gomes e Mandrá15, fizeram um estudo entre os alunos de fonoaudiologia de uma universidade governamental que mostra que $72,8 \%$ da população 
estudantil afirma que "em todas as disciplinas do curso" os docentes incentivam a leitura, o que pode também ocorrer no presente caso.

De qualquer forma, estes resultados podem ser muito úteis se se tornarem parâmetros para comparações em novos estudos sobre os resultados de estratégias implementadas pela faculdade ou da evolução desses hábitos em pesquisas futuras ou de outras variáveis de interesse como, por exemplo, uma alteração no perfil dos ingressantes.

\section{CONCLUSÃO}

Em síntese, pode-se afirmar que a população de estudo é representativa de toda a faculdade e que os resultados apresentados podem ser generalizados para os estudantes matriculados na instituição do estudo. O perfil dos constituintes e das variáveis contextuais da amostra do presente estudo não diferem muito de outras populações similares estudadas no Brasil o que representa uma conclusão importante considerando a carência de investigações da região norte do país. É importante que se destaque, também que, como se compararam dois grupos com faixas etárias diferentes, a coerência dos dados refletiu o aumento natural da idade e da maturidade do grupo o que argumenta a favor da qualidade das informações obtidas. Com referência ao objetivo do presente estudo, verificou-se que a comparação entre os hábitos de leitura dos estudantes ingressantes e concluintes produziu alguns destaques importantes que podem indicar uma influência positiva da instituição em estudo, mas uma afirmação desse fato só pode ser demonstrada por pesquisas específicas.

\section{REFERÊNCIAS}

1 - Davidovitch N, Yavich R, Druckman E. Don't Throw Out Paper AndPens Yet: On The Reading Habits Of Students. Journal of International Education Research. 2016;12(4):129-143.

2 - Baptista RM, et al. Práticas de leitura e compreensão de texto no $6^{\circ}$ e $7^{\circ}$ anos do ensino fundamental. Estudos de Psicologia, Campinas. 2016;33(1):173-182.

3 - Freire P. A Importância do ato de ler. 3. ed. São Paulo: Cortez Editora, 1983.

4 - Witter GP (Org.). Psicologia, Leitura e Universidade.
Campinas, SP: Alínea Editora, 1997.

5 - Witter GP (Org.). Leitura: Textos e Pesquisas. Campinas, SP: Alínea Editora, 1999.

6 - WITTER GP(Org.). Leitura e Psicologia. Campinas, SP: Alínea Editora, 2004.

7 - Tourinho C. Refletindo sobre a dificuldade de leitura em alunos do ensino superior: "deficiência" ou simples falta de hábito? Revista Lugares da Educação, Bananeiras/PB. 2011;1(2):325-346.

8 - Silva MF, et al. O hábito de leitura dos universitários. Revista Leitura. 2015;2(56):60-73.

9 - Araujo EHE de, Vanzella E, Brambilla A. Hábito de leitura dos estudantes de turismo. In: Jornada acadêmica Estácio 2016. Anais [...]. João Pessoa: Revista Mangaio Acadêmico. 2016;1(2).

10 - Garcia AKA, Moraes A, Guariente MHD de M. Perfil de estudantes de um curso de enfermagem do Sul do Brasil: características dos hábitos de leitura e estudo. Semina: Ciências Biológicas e da Saúde, Londrina. 2016;37(2):47-54.

11 - Lustosa SS, et al. Análise das práticas de letramento de ingressantes e concluintes de uma instituição de nível superior: estudo de caso. Revista CEFAC, São Paulo. 2016;18(4):1008-1019.

12 - Nascimento FP, Franco SAP. Conhecimento de mundo por meio da leitura digital: um estudo com universitários. RIAEE - Revista Ibero-Americana de Estudos em Educação. 2017;12(2 esp):1511-1523.

13 - Fernandes RCG, Maia RF. Comportamento leitor de universitários: um estudo com alunos de Administração e computação. In: Simpósio Internacional de Letras e Linguística. Anais [...]. Uberlândia 2913: EDEFU 3(1).

14 - Santos FMFC, Nunes MSC. Comportamento leitor dos acadêmicos do curso de biblioteconomia e documentação da Universidade Federal do Sergipe. Biblionline, João Pessoa. 2014;10(2):66-80.

15 - Gomes APS, Mandrá PP. Hábitos de leitura de estudantes do Curso de Fonoaudiologia. Rev. Grad. USP. 
2017;2(3)13-17.

16 - Alves FIAB, et al. Estudo dos fatores que dificultam a leitura e a escrita dos estudantes de Ciências Contábeis. Revista Contribuciones a las Ciencias Sociales oct 2018. Disponível em: https://www.eumed.net/rev/ cccss/2018/10/fatores-dificultam-leitura.html//hdl.handle.net/ 20.500.11763/cccss1810fatores-dificultam-leitura 